\title{
PELATIHAN TERAPI BERMAIN BAGI RELAWAN KANKER UNTUK MENINGKATKAN DUKUNGAN SOSIAL BAGI ANAK KANKER
}

\author{
(The Therapy Plays Training For Cancer Volunteers To Improve Social \\ Support For Children With Cancer)
}

\author{
Feriana Ira Handian 1), Lilla Maria ${ }^{2)}$, Dian Samtyaningsih ${ }^{3)}$ \\ ${ }^{1}$ Departemen Keperawatan Anak, STIKES Maharani, Malang \\ Email: ferianaazar@gmail.com \\ ${ }^{2}$ Departemen Keperawatan Anak, STIKES Maharani, Malang \\ Email: lilla_mk@yahoo.com \\ ${ }^{3}$ Prodi DIII Kebidanan, Stikes Maharani Malang \\ Email: fidiatama@gmail.com
}

\begin{abstract}
ABSTRAK
Terapi bermain merupakan salah satu sarana untuk menurunkan stress hospitalisasi pada anak kanker. Relawan komunitas Sahabat Anak Kanker (SAK) adalah salah satu pihak yang selama ini telah memiliki program bermain bagi anak kanker, akan tetapi dalam perjalanannya masih memiliki kendala karena kurangnya SDM yang memahami secara menyeluruh tentang terapi bermain pada anak sakit. Program ini dilaksanakan dengan memberikan pelatihan terapi bermain bagi relawan anak kanker untuk meningkatkan kualitas pendampingan terhadap anak kanker oleh SAK. Pelatihan dilakukan bagi 21 relawan dengan sesi pemberian materi, demonstrasi dan observasi langsung saat pendampingan dengan anak kanker dalam program bermain di Rumah Sakit. Dari hasil didapatkan bahwa pada setelah pelatihan, kemampuan relawan meningkat dalam aspek persiapan terapi bermain, proses pendampingan dan mencatat atau mengevaluasi respon anak. Kendala terbesar adalah pada pemantauan respon anak karena masih banyaknya relawan yang bukan berasal dari tenaga kesehatan dan kesulitan dalam memahami data rekam medik yang dimiliki oleh pasien terkait hasil laboratorium. Untuk waktu mendatang perlu dipertimbangkan untuk peningkatan kemampuan relawan dalam berkomunikasi dengan tenaga kesehatan saat melaksanakan terapi bermain.
\end{abstract}

Kata kunci : Terapi bermain, Pelatihan, Relawan, Kanker

\begin{abstract}
Play therapy is one of the means to reduce the stress of hospitalization in children with cancer. The volunteers of the Sahabati Anak Cancer (SAK) community are one of communities who had a therapeutic program for children with cancer, at present they still have problems due to a lack of human resources who comprehensively understand play therapy in children. This program carried out by providing play therapy training for child cancer volunteers to improve the quality assistance for cancer children. The training conducted for 21 volunteers with material giving sessions, demonstrations and direct observation during mentoring with cancer children in playing program at hospital. It was found that after training, the ability of volunteers increased in preparation for play therapy, mentoring process and recording or evaluating children's responses. The biggest barrier is monitoring children response because there are many volunteers who are not from health professional and difficulty in understanding medical record test held by patients related to laboratory results. It needs to be considered to increase the ability of volunteers to communicate with health workers during play therapy session.
\end{abstract}

Keyword : Play Theraphy, Training, Volunteer, Cancer 


\section{PENDAHULUAN}

Saat seseorang mengalami suatu kondisi yang dianggap menyimpang dari perilaku atau kondisi aslinya, maka dibutuhkan intervensi yang sering disebut dengan terapi. Terapi ini secara umum terbagi menjadi dua, yaitu terapi jangka pendek dan terapi jangka panjang. Berdasarkan kondisi yang dihadapi, pada keadaan penyimpangan ringan maka yang dibutuhkan adalah terapi jangka pendek, akan tetapi pada kondisi yang lebih berat, dibutuhkan intervensi yang lebih kontinyu dan terjadwal dalam kurun waktu yang lebih panjang, hal ini dapat dipenuhi dalam bentuk terapi yang kedua yaitu terapi jangka panjang (Adriana, 2011).

Terapi bermain adalah aktivitas yang dilakukan untuk intervensi khusus bagi anak. Pada kegiatan ini, anak diintervensi dengan mengondisikan anak berada pada situasi bermain. Hal ini dilakukan agar anak lebih tenang dan santai sehingga anak mampu mengekspresikan perasaannya (Pratiwi 2011). Secara umum terapi bermain ini dapat dilakukan pada anak sakit di rumah sakit untuk menurunkan stress hospitalisasi (Carpenter, 1998). Dengan kegiatan terapeutik selama permainan maka anak akan dibawa pada kondisi yang santai dan rileks terutama terhadap persiapan prosedur atau tindakan selama di rumah sakit (Steele, 1981). Terapi bermain juga telah menunjukkan hasil dapat menurunakan stress hospitalisasi pada anak terhadap kecemasan proses perioperatif dan menurunkan nyeri post operatif (Amstrong \& Aitken,2000). Pada penelitian lainnya terhadap anak autis, kegiatan terapi bermain yang dilakukan dengan minimal 5 sesi dapat menurunkan skor perilaku autistik yang terjadi pada anak (Priyadi, Handian, \& Yudiernawati, 2016).

Pada anak dengan kanker, salah satu intervensi yang digunakan untuk menurunkan stress hospitalisasi adalah dengan terapi bermain. Pada berbagai penelitian yang dilakukan dengan meta analisis dari praktek terapi bermain pada prosedur invasif di beberapa negara, menunjukkan bahwa terapi bermain ini secara umum masih menghasilkan hal yang bervariasi dalam output capaian kesehatan, memiliki kelebihan dan kelemahan, misalnya adalah untuk mencapai hasil yang maksimal, observasi yang dilakukan kepada anak harus difokuskan pada satu sesi atau variabel misal perilaku anak oleh satu observer dan variabel lain misalakan stress oleh observer lainnya (Silva, Austregésilo, Ithamar, \& Lima, 2017).

\section{METODE}

Kegiatan pelatihan ini dilakukan dengan tiga kali sesi pelatihan untuk 21 orang relawan Sahabat Anak Kanker (SAK) Malang. Sesi 1 adalah materi klasikal, sesi II untuk demonstrasi terapi bermain dan sesi III dengan praktik langsung saat aktivitas bermain dengan anak di ruang bermain sekretariat Sahabat Anak Kanker/Ruang bermain IRNA 4 RSUD Saiful Anwar Malang. Pada sebelum pelatihan peserta akan dinilai kemampuannya dengan ceklist kemampuan individu yang selama ini diterapkan selama mendampingi anak kanker bermain di ruang bermain dan sesi post pelatihan penilaian dilakukan dengan penilaian kelompok yang meliputi aspek persiapan, pelaksanaan pendampingan terapi bermain dalam program bermain SAK di rumah sakit dan kemampuan relawan dalam memantau respon anak selama durasi terapi bermain.

\section{HASIL DAN PEMBAHASAN}

Dari hasil pelatihan menunjukkan bahwa terdapat peningkatan skor kemampuan relawan dalam melaksanakan terapi bermain dengan data seperti pada gambar 1 .

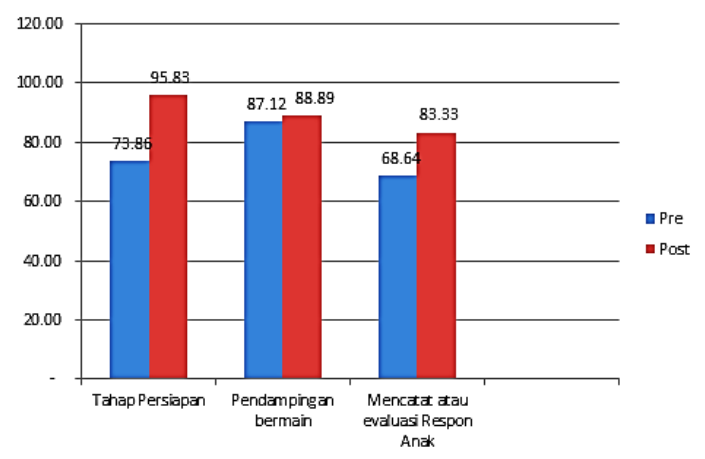

Gambar 1. Penilaian Kemampuan Relawan Pre dan Post Pelatihan Terapi Bermain

Dari gambar diatas dapat ditunjukkan bahwa terdapat perubahan rerata nilai kemampuan relawan pada tahap persiapan sebesar 21,97 poin, pada tahap pendampingan bermain sebesar 1,77 poin dan tahap mancatat atau evaluasi respon anak dengan peningkatan nilai sebesar 19,69 poin. Berdasarkan penilaian kompetensi $(\mathrm{NA}>80)$ 
maka terdapat perubahan kemampuan pada aspek tahap persiapan dan aspek pencatatan atau evaluasi respon anak yang semula tidak mampu menjadi mampu.

Kemampuan relawan dalam tahap persiapan menunjukkan perubahan kemampuan dari tidak mampu menjadi mampu. Penilaian aspek ini mencakup kemampuan relawan dalam menjelaskan pentingnya bermain bagi anak atau orangtua, memilih anak yang tepat untuk diajak terapi bermain, apakah cukup di tempat tidur ataukah di ruang bermain, menyiapkan alat bermain dan mengajak anak berkenalan dan memperkenalkan diri. Pada sebelum pelatihan, sebagian besar relawan tidak menjelaskan kepada orangtua tentang pentingnya bermain bagi anak atau orangtua dan tidak mengajak anak berkenalan dalam satu kelompok bermain.

Di tahap pendampingan bermain, aspek yang dinilai adalah pemilihan permainan yang tidak memperberat penyakit, durasi bermain yang tidak lebih dari 30 menit dan tidak memerlukan energi yang berlebihan. Pada tahap ini sebagian besar relawan sudah menerapkan dengan benar, hanya sebagian kecil relawan yang membiarkan durasi raktu lebih dari 30 menit karena ketidaktahuan tentang pengaruh durasi waktu terhadap kestabilan kondisi fisik anak. Pada aspek ini kemampuan relawan sudah baik, tapi masih perlu ditingkatkan agar relawan mengingat waktu bermain dan tidak terlena dengan keinginan anak untuk terus bermain.

Tahapan yang ketiga adalah pada pemantauan atau evaluasi respon anak sebelum bermain. Pada aspek ini hampir seluruh relawan tidak melakukan pemeriksaan data laboratorium sebelum dilakukan terapi bermain, terutama kadar $\mathrm{Hb}$ pada anak kanker yang akan diajak ke ruang bermain. Kendala yang dihadapi adalah kurangnya kemampuan relawan karena tidak seluruh relawan memiiki latar belakang kesehatan. Hal lain yang masih kurang saat sebelum pelatihan adalah cara mengetahui tanda anemia, memeriksa suhu dan respon anak. Pada setelah pelatihan, kemampuan ini sudah meningkat, akan tetapi keterbatasan relawan dalam menjangkau dan menerjemahkan data laboratorium masih menjadi hambatan bagi kelompok.
Keberhasilan terapi menurut Maulana (2007) tergantung dari beberapa faktor seperti berat atau ringannya gejala, umur, kecerdasan, bicara dan berbahasa, serta intensitas dari terapi itu sendiri. Kesertaan kelompok dukungan sosial ini penting bagi anak kanker agar anak-anak menjadi lebih mudah beradaptasi dan tidak bosan dengan situasi rumah sakit (Handian et al., 2017).

\section{KESIMPULAN DAN SARAN}

Kemampuan relawan dalam terapi bermain mengalami kenaikan skor pada sebelum dan setelah pelatihan, dengan kenaikan mulai tertinggi sampai terendah adalah pada tahap persiapan, pelaksanaan dan evaluasi atau pemantauan kondisi anak.

Dari hasil pelatihan ini perlu dilakukan pemantauan secara berkala oleh komunitas tentang pelaksanaan terapi bermain di ruang bermain dan meningkatkan pengetahuan relawan tentang istilah medis dan pemeriksaan fisik sederhana untuk memantau kondisi fisik anak kanker selama sesi bermain.

\section{UCAPAN TERIMA KASIH}

Program ini sepenuhnya didukung dengan pendanaan dari Kemristekdikti T.A 2018

\section{REFERENSI}

Armstrong TS, Aitken HL. (2000). The developing role of play prepa- ration in paediatric anaesthesia. Paediatr Anesth.;10: 1---4.

Carpenter (1998). Developing A Pediatric Patient/Parent Hospital Preparation Program. AORN J. 1998;67:1042---6

Handian, F. I., Fitria, Y., Mahmudatul, D., Falah, R., Stikes, ), \& Malang, M. (2017). Mendukung Kepatuhan Pengobatan Dengan Berbagi Kebahagiaan Dan Menjadi Sahabat: Studi Kasus Di Komunitas Sahabat Anak Kanker Malang, Indonesia. The indonesian journal of health SCIENCE, 8(2). Retrieved from http://jurnal.unmuhjember.ac.id/index.p hp/TIJHS/article/viewFile/870/692

Priyadi, H., Handian, F. I., \& Yudiernawati, A. (2016). Play Theraphy Influences Autistic Behavior on Children With 
Autism.

Silva, R. D. M. da, Austregésilo, S. C., Ithamar, L., \& Lima, L. S. de. (2017). Therapeutic play to prepare children for invasive procedures: a systematic review. Jornal de Pediatria, 93(1), 616.

http://doi.org/10.1016/j.jped.2016.06.00 5 